\title{
Towards a Positive Psychology of Buildings and Workplace Community:the Positive Built Workplace Environment
}

\author{
Anthony M. Grant ${ }^{1}$ (D) Sean A. O'Connor ${ }^{1} \cdot$ Ingrid Studholme $^{1}$
}

Accepted: 12 August 2019/Published online: 17 August 2019

(C) Springer Nature Switzerland AG 2019

\begin{abstract}
Positive psychology has produced useful research findings that can offer insights into the psychological factors that promote flourishing in peoples' personal life and in workplace settings. However, there has been little work explicitly linking positive psychology constructs to the physical built workplace environment. This paper explores the notion of a positive psychology of workplace buildings and introduces the concept of the Positive Built Workplace Environment (PBWE). We explore the links between the physical attributes of well-designed sustainable contemporary workspaces, performance and well-being and the humanistic values central to the positive organisational enterprise. Given the rise in the use of activity-based flexible offices and coworking spaces this is an area where positive psychology can make important contributions. Using a qualitative case study approach we explore the lived experience of people who work in physical and psychological environments that stimulate and support innovative, agile and collaborative workplace cultures. Five key categories emerged from the interview data: The impact of the physical environment on performance, engagement and gratitude; the role of values-based leadership in extending the utility of activity-based working; expressions of purpose, pride and well-being; issues in making a transition to a new way of working; and how physical spatial change can be a facilitator of corporate cultural change. We present three models that may be of use in exploring the PBWE from a positive psychology perspective: 1) the Positive Built Environment Scale which uses Self-determination Theory as a means of measuring the psychological aspects of the PBWE; 2) an adaptation of Maslow's Hierarchy of Needs as a psychological framework with which to evaluate the physical aspects of the PBWE; and 3) a theoretical model of the relationships between the constructs in this paper. As the nature and pace of work evolves, we hope that our paper helps further develop our understanding of how to develop positive workplace environments that support organisational and individual development in a sustainable, humanistic fashion.
\end{abstract}

Keywords Activity-based workplace · Positive Psychology · Self-determination Theory · Positive Organizations · Workplace Cultures

Anthony M. Grant

anthony.grant@sydney.edu.au

Extended author information available on the last page of the article 


\section{Introduction}

This paper explores the notion of a positive psychology of workplace buildings and introduces the concept of the Positive Built Workplace Environment (PBWE). Positive psychology as a discipline has produced useful research findings that can offer insights into the psychological factors that promote human flourishing in peoples' personal life and in workplace, organisational and educational settings (e.g., Cameron et al. 2003; White and Waters 2015). However, to date there has been little work explicitly linking positive psychology constructs to the built workplace environment. Our aim is to begin to explore the links between the physical attributes of well-designed sustainable contemporary workspaces, employee performance and well-being, and organisational culture, and the humanistic values central to the positive organisational enterprise. We hope to further stimulate interdisciplinary debate and research into the practical conditions that enhance well-being and flourishing in peoples' working lives.

Firstly, we discuss the relationship between the physical workplace environment and organisational performance and we explore understandings of the notion of the 'flourishing workplace'. We then present interviews from staff and tenants at International Towers ${ }^{1}$ in Sydney which is used in an exploratory case study to examine the lived experiences of people who work in such positive workplace environments. International Towers is an innovative commercial hub situated on Sydney Harbour which has been specifically designed and built to provide a positive physical and psychological environment that stimulates and supports innovative, agile and collaborative workplace cultures. It is these features that make International Towers a suitable location for this research.

We then present three models that may be of use in exploring the positive built workplace environment from a positive psychology perspective: 1) the Positive Built Environment Scale which uses Self-determination Theory (Deci et al. 2017) as a framework for a proposed questionnaire with which to measure the psychological aspects of the PBWE; 2) an adaptation of Maslow's Hierarchy of Needs (Maslow 1968) as a psychological framework with which to evaluate the physical aspects of the PBWE; and 3) a theoretical model of the relationships between the various constructs discussed in this paper.

\subsection{The Physical Workplace Environment and Organisational Performance}

The physical workplace environment has long been recognised as having a significant impact on organisational performance. Consequently, organisations seek to work in buildings that provide a space that can better facilitate individual, team and organisational performance. Such performance enhancement may occur through providing a physical workplace environment that maximises the effective use of space and resources. Over the years organisations have tried a wide range of design approaches including cellular office layouts, open-plan designs, hot-desking, and more recently "New Ways of Working" (NWoW) and activity-based flexible offices (AppelMeulenbroek et al. 2011).

\footnotetext{
${ }^{1}$ International Towers Sydney Trust, which owns Tower Two and Tower Three, will be referred to throughout this document as International Towers.
} 
NWoW and shared activity-based workplaces, including activity-based flexible offices (A-FOs), are increasingly the norm worldwide. These are characterized by an open-plan layout and desk sharing with few rooms designated for private meetings. Such A-FOs tend to look more like a hotel, home or café-type space with colourful lounges and secluded nooks to hold private meetings, in and with open shared table spaces for collaborative work. In many ways A-FOs are the antitheses of the traditional "formal" hierarchically-structured office environment which was developed many decades ago and in many cases no longer serve the needs of the contemporary and emerging workplace. A-FOs are highly popular in contemporary organisations and initial reports suggest that they can be positive and energising places to work. However, there has been little published research on the specific effects of A-FOs or other nontraditional and innovative office working environments (Ruostela et al. 2015) on performance, well-being or other important metrics such as organisational culture and employee engagement.

Whilst it is broadly recognized that the physical working environment constitutes a source of 'affective events' that can shape office workers' behaviours and attitudes (Ashkanasy et al. 2014), the research, such as it is, is not clear-cut. For example, Brunia et al. (2016) found that there were large differences in employee satisfaction between physically-similar activity-based offices. Brunia et al. (2016) reported that critical success factors included a spatial layout that supported and facilitated communication and concentration, an attractive architectural design, visually pleasing and ergonomic furniture, as well as adequate storage facilities for personal effects. These sort of office working conditions can be seen as analogous to basic 'hygiene' factors (Herzberg 1964) - factors, that if not satisfactory will cause disengagement and poor performance. Moving beyond physical 'hygiene' factors, Brunia et al. (2016) also identified a range of motivating factors that were associated with greater success. These included design features that addressed psychological issues such as one's need for privacy, thermal comfort, and exposure to abundant daylight, as well as access to a pleasant and stimulating view.

The above factors can create the positive and flexible physical workplace environment necessary for high performance. However, although a positive and flexible physical environment is undoubtedly important, it may not be sufficient to create a flourishing workplace (Grant 2006; Grant 2012).

\subsection{The Physical Aspects of a Flourishing Workplace: Sustainable High Performance}

A flourishing workplace can be understood as a workplace that is designed and operated in a way that provides the optimal physical, psychological and cultural conditions that enable employees to deliver consistently high performance, whilst simultaneously maintaining and enhancing employees' well-being and creating a constructive positive organisational culture. From this perspective is it the adroit pairing of the right type of built environment and physical layout with the right psychological or sociological aspects that creates the potential for a sustainable, high performance flourishing workplace.

From a physical perspective we know that the quality of the employee's working environment has a significant impact on their level of motivation and their individual and team performance. The extent to which employees positively engage with their 
physical environment has a significant influence on work errors, levels of innovation and collaboration and well as relationships with their supervisor or managers and ultimately even their intention to quit or remain on the job (Chandrasekar 2011).

Although it is difficult to draw direct quantative comparisons between different organisations, industry sectors and country locations, a broad overview strongly indicates a strong relationship between good design and work performance, suggesting in turn, a significant return on investment. Surveys are the most common research method in this area. A USA survey of 2013 professional managers from a range of business sectors found that $89 \%$ of respondents indicated that effective workplace design is important in increasing employees' productivity - with respondents estimating a potential productivity increase of up to $21 \%$ (Leblebici 2012). Along similar lines, surveying 200 middle and senior UK managers from legal, media and functional services sectors Gensler (2005) found that that a well-designed working layout could increase selfreported productivity by $19 \%$. Mulville et al. (2016) found strong links between positive ambient office environmental conditions (e.g., access to sunlight, views, air conditioning), positive workplace behaviours and productivity in the workplace.

The research on specific aspects of 'green' offices also delivers some persuasive metrics. Allen et al. (2016) found that compared to 'standard office conditions' improved air quality could increase performance on cognitive tasks by $61 \%$, with over $100 \%$ increase found in some cases. Performance on cognitive tasks was assessed using the Strategic Management Simulation (SMS) software tool. This is a well-validated, computer-based test that has been designed to test the effectiveness of managementlevel employees through evaluation of their higher-order decision making (Streufert et al. 1988). The SMS measures decision-making performance in nine domains: basic, applied and focused activity level, task orientation, crisis response, information seeking and usage, breadth of approach and strategy. MacNaughton et al. (2015) studied employees in 10 different green-certified buildings and found that employees had $30 \%$ less respiratory complaints and fewer headaches. In addition, employees performed nearly $27 \%$ better on cognitive function tasks as measured by their performance on the SMS cognitive test. Also, as measured by a sleep quality wristband, they also slept better at night. Such green office environments can deliver significant financial returns on investment. MacNaughton et al. (2015) found that an investment of US\$40 per person, per year on indoor air quality, resulted in a US\$6500 increase in employee productivity.

\subsection{The Psychological Aspects: Positive Leadership in a Flourishing Workspace}

From a psychological perspective, vital aspects contributing to a high performance workplace include the organisation's culture and values, and the social contracts between management and employees. The relationship between these and employee engagement is a crucial one (van Elst and Meurs 2015). Engaged employees are more productive, have higher job performance (Guthrie 2001) take less sick days, have higher customer satisfaction ratings, are less likely to leave their job (Bakker 2011), and hold themselves and their organisations in higher esteem (Cameron and Dutton 2003; Pierce et al. 2016).

Leadership style is a key contributing factor here. Positive leadership (Cameron 2012) is a recently emerging leadership concept and refers to the application of the 
principles of positive psychology in leadership contexts, and has been informed by the fields of positive organisational scholarship (Cameron and Dutton 2003), positive psychology (Seligman and Csikszentmihalyi 2000), and positive change (Srivastva and Cooperrider 1999). The four key components of positive leadership as articulated by Cameron (2012) are 1) the cultivation of a positive organisational climate, 2) positive relationships, 3) positive communication and 4) positive meaning at work.

Thus a key part of the positive leadership construct is a focus on human virtues, strengths and positive characteristics such as transcendence, temperance, wisdom, creativity, courage, citizenship, teamwork, leadership, social intelligence, fairness, and humility (Cameron 2012). This is not to say that positive leadership ignores problems, rather, presenting problems are seen as being useful precursors for the identification and enactment of solutions (Grant 2013). This is also not to imply that focusing on positive traits will somehow eliminate negatives aspects of the workplace, but here the leader's focus is on encouraging positive traits and making work a personally meaningful experience, rather than being primarily concerned with identifying errors or shortcomings in employees. Of course, this approach is not without its critics (e.g., Lomas and Ivtzan 2016; Miller 2008). Nevertheless there is emerging research to show that this more proactive, humanistic and encouraging style of organisational leadership can indeed be highly effective and profitable in the right context. For example Cameron, Bright, and Caza (2004) reported that organisations with higher virtuousness scores (compassion, trust, forgiveness, optimism, integrity) had significantly higher productivity, quality outputs, profitability, quality, customer retention, and lower employee turnover. Along similar lines Datta (2015) found that an Authentic Leadership style, defined as a pattern of leader behaviour that draws upon and promotes both positive psychological capacities and a positive ethical climate (Walumbwa et al. 2008) was strongly associated with managerial effectiveness, enhanced organisational performance, satisfaction of follower needs, and improvement in the quality of work life.

\subsection{Important Synergies between Positive Leadership and the Positive Built Environment}

There are also some important potential synergies between positive leadership and the positive built environment. Although there has been little to no research exploring the synergies between leadership style and the built workplace environment, we see this as the logical extension of the current work on positive leadership. To create a truly flourishing workplace we need to extend Cameron (2012) four-part framework of a positive organisational climate, positive relationships, positive communication and positive meaning at work, by the addition of the previously discussed notion of a fifth factor: a positive built workspace environment (PBWE).

In short, a PBWE can be understood as one that is designed and operated in a way that provides the optimal physical and psychological conditions and resources to enable employees to consistently deliver high performance and maintain personal and organisational well-being. The notions of sustainability and well-being are central to this understanding. A PBWE is one that promotes sustainable high performance - and this means that it should promote both high performance and employee well-being. A focus purely on high performance without considering aspects of well-being quite predictably leads to employee disengagement and burnout (Spence and Grant 2013). 
The physical building itself needs to be designed with sustainability in mind. However, the notion of the PBWE extends the current concepts underpinning 'green' buildings. Green buildings incorporate design and construction practices that significantly reduce or eliminate the negative effects of buildings on the environment and on occupants in key areas such as; sustainable site planning: safeguarding water and water efficiencies; energy efficiency and renewability; conservation of material and resources and indoor environmental quality (Yudelson 2009). The notion of the PBWE extends these physical attributes and incorporates the notion of a values-driven built environment; that is, a physical environment that embodies and represents a specific set of positive values. In short, the PBWE should shape and promote a positive or 'growth' mindset (Dweck 2016).

We typically think of 'leadership' as being confined to a specific organisation's employees or management. However, 'leadership' in the PBWE goes beyond the tenant organisation's designated leadership team (for example, the tenant organisation's CEO, $\mathrm{CFO}$, and line managers) - and also includes people from beyond the organisation such as (for example) the building developers, design team, property managers as well as the building service teams. The re-defining of the relationships between those involved in commercial real estate management and a building's tenants has important ramifications.

Typically to date the relationship between commercial real estate agents or managers and their tenants has been overly-transactional (Bishop 2004) with most agents focusing on aspects such as value for money, service charges, leasing processes and building maintenance issues. However, in interviewing 1334 office tenants in the UK Sanderson and Edwards (2016) found that such commercial tenants are increasingly looking for better quality relationships with their property managers; relationships that clearly demonstrate empathy, social responsibility, and a solid understanding of their business needs and corporate values as well as the 'business as usual' professional services. Sanderson and Edwards's (2016) redefining of the tenant-property manager's relationship demands that property managers in effect become part of the tenant organisation's leadership system: In a very real way, the contemporary property manager needs to display good positive leadership if they are to establish a true PBWE.

To date there has been very little research that has conjointly explored the above issues (Sanderson and Edwards 2016). The aim of the present research was to explore the above issues from a perspective of a positive psychology of workplace buildings and community.

\section{Illustrative Case Study}

The above conceptual discussion focuses on the interactions between the positive built environment and positive leadership and the concept of a flourishing workplace. In order to ground this conceptual discussion we now present an illustrative case study in which we explore the above concepts.

The location for this case study is the certified 'six star' green International Towers an innovative commercial hub situated on Sydney Harbour that accommodates approximately 23,000 office workers and a range of leading retailers and restaurants. The physical features of the built workplace environment include abundant light and a sense 
of space, high ceilings, large adaptable workspaces, premier views over Sydney Harbour, and cutting edge Information and Communications (ICT) infrastructure amongst other features. In short, these buildings and the associated harbour-side precincts have been designed to provide a positive physical environment that stimulates and supports innovative, agile and collaborative workplace cultures and as such aims to be a stimulating and engaging workplace environment.

\subsection{The 'Carpe Diem' Space and Community}

In addition to the physical aspects of International Towers, the International Towers building management has articulated a set of positive values with the aim of having them being implicitly associated with the building and its precincts. These values include concepts such as respect for indigenous heritage and culture, sustainability, innovation and collaboration as well as the values associated with positive leadership (Cameron 2012). This inclusiveness is echoed in the choice of tenants which explicitly includes small start-ups, not-for-profit organisations, as well as large professional services firms and corporate organisations such as banks. The idea here is to foster collaboration and interaction between organisations that would not normally come into contact with each other to create a creative hub that transcends normal ways of occupying and working within a building and its associated precincts.

Crafting this way of working requires a different type of relationship between all stakeholders. The aim here is to create a culture within the building that is collaborative and inclusive from the outset. The focus is on engaging others in a mutual dialogue, working towards a shared vision beyond conventional organisational boundaries. There is a significant focus on honouring the Aboriginal heritage of the site, and tapping into a diversity of perspectives as a way to catalyse meaningful change, with the overall aim of leaving the world a better place.

The term 'Carpe Diem' community was coined by the International Towers building property managers to encapsulate the above cultural ideals. In short, 'Carpe Diem' is about working towards a higher purpose and crafting a community of like-minded custodians. While 'Carpe Diem' is about seizing the day and being mindful in the present, it is also about taking positive action for the future, to do all one can do today to shape a better future. In this way people are positioned as being custodians of the future. Clearly, such utopian concepts stand in stark contrast to typical experience of commercial real estate transactions. 'Carpe Diem' was initially simply a name for this development project, but the notion gained significant traction and has now evolved into a formal curated tenancy model. Note: The term 'Carpe Diem' is used to describe the culture associated with the International Towers building rather than the building itself.

The International Towers building managers refer to their role as one of a curator. The term 'curate' means to "select items and care for items from among a large number of possibilities for other people to consume and enjoy" (Macquarie Dictionary). Typically, the term curate refers to domains such as museum, art or fashion. The somewhat unusual use of the term 'curate' by the International Towers building managers in relation to the buildings and its precincts imparts a sense of caring and custodianship of the building and its associated cultural connotations that goes beyond the usual building manager's relationship with their tenants or their building. 


\subsection{Differences between 'Carpe Diem' and Co-Working Spaces}

Co-working spaces are shared 'rent-by-the-month' working spaces where entrepreneurs, small firms, freelancers and start-ups can acquire the basic facilities to enable them to start and grow their businesses (Fuzi 2015). This is one of the fastest growing areas of global commercial real estate, and the creative and ad hoc nature of these workspaces is attractive to many.

Coworking spaces can typify the community-based aspects of NWoW and shared activity-based workplaces. Such community-based interactive workspaces have been shown to produce greater levels of innovation, creativity, teamwork and better quality work (Johns and Gratton 2013). However, there are some very important differences between coworking spaces and the 'Carpe Diem' approach.

In coworking spaces, individuals rent table, desk, or office space as they need it on a month to month basis, and any individual or business can rent desk or office space. There is no overt oversight by the coworking building managers to ensure a range of different business within any one space, and no overt effort to build synergy at a systemic level between different tenants. In coworking spaces, collaboration and synergies between different tenants may emerge due to physical proximity, but such collaborations and synergies are by-products of physical proximity rather than an outcome that has been intentionally designed and implemented in the workspace by the designers or building managers.

In the 'Carpe Diem' approach the building layout itself is specifically designed to maximise 'serendipitous creative contacts' between people from different organisations. There is explicit intention at the systemic level to create collaboration between different businesses. For example, there are minimal physical or visible barriers between different businesses workspaces and there are many shared resources which are designed to act as attractor points.

Importantly, there are barriers to entry into the 'Carpe Diem' community. Not just anyone can rent space. Tenants are required to go through a screening and induction process to ensure that their organisation's values and culture are a good fit with the 'Carpe Diem' philosophy and to also minimise commercial competition between tenants within the workspace. This last point is important but often overlooked. In a study of coworking spaces Bouncken et al. (2018) found the professional and social dynamics between competing businesses in coworking spaces can easily result in the creation of conflict, jealously, and distrust, and this is particularly the case where other tenants in the coworking space are competitors in the same line of business (Bouncken et al. 2018). In contrast, collaboration and values alignment are key 'Carpe Diem' ideals.

\subsection{The ‘Carpe Diem' Induction Processes}

In order to maximise the probability of good alignment between the 'Carpe Diem' values and culture and tenants, the International Towers building managers and designers engage potential tenants in an in-depth collaborative dialogue and a formal induction process. This goes beyond typical transactional real estate negotiations that focus on value for money, building services and maintenance-related issues. In keeping with this collaborative ethos, the International Towers building tenants are referred to as 
tenant-partners. These conversations focus on cultural fit and helping potential International Towers tenant-partners engage in both a physical and cultural change process. The physical change process encompasses the normal issues related to moving such as office fit-out, logistics and the like. The emphasis on the cultural or psychological change process involves assessing one's readiness for change, articulating one's vision, committing to sustainable change, and then engaging in the change process. All of these have been demonstrated to be vital factors in successfully navigating individual and organisational change (Prochaska 2000).

\section{Method Section}

Sixteen qualitative interviews were conducted during March 2017 to May 2017 with tenant-partners, staff, and other key stakeholders in the community at International Towers. There were four categories of interviewees; tenant-partner leadership; tenantpartner employees; International Towers service staff; and International Towers management and leadership. The interviews were conducted by two experienced qualitative researchers, one with a Masters level degree in Coaching Psychology, the other with a $\mathrm{PhD}$ in Positive Organisational Coaching. In order to minimise potential bias we drew on Morse et al.'s (2002) recommendations on verification strategies for establishing reliability and validity in qualitative research. As researchers we critically examined own roles, potential biases and influence during the formulation of the research questions, our choice of location for the interviews (ensuring a neutral and private location with no disturbances) and well as during the data collection process itself (that is, before and after each interview).

Interviews ranged from 45 to $90 \mathrm{~min}$ and were recorded and then professionally transcribed. Open-ended probe questions covered issues such as; elements of the International Towers environment that either support or hinder performance; the process of transition and adaptation to International Towers; culture and wellbeing; the impact (or lack of impact) of the mindset and values espoused within International Towers on the tenant-partner's organisation; any unexpected positive or negative impact; and any suggestions for future improvements.

In conducting the data analysis we utilised a general inductive approach (Thomas 2006). The transcripts were read several times to identify themes and categories. All three researchers (this paper's authors) read the transcripts independently. The researchers then met and shared their individual perspectives. After discussion between the three researchers a coding frame was developed. We did this by looking for the shared core meanings and key themes evident in the texts which were clearly relevant to the evaluation and research objectives. As the transcripts were read and re-read and our discussion continued, some original codes were deemed redundant, and as new codes emerged the redundant codes were incorporated into the emerging higher order constructs. The coding frame was then changed accordingly and the transcripts were then re-read again with the final themes in mind. We were particularly focused on hearing the "voices" of the participants as well as the specific language they used to convey their lived experience (Blair 2015). We used diagrams and flow charts to link key themes as themes and categories emerged. We then developed a hierarchical category system in which the higher order constructs consisted of five key categories 
relevant to the research objectives. On the few occasions that the researchers had differing perspectives we discussed these until a coherent understanding and shared agreement was reached (Neuendorf 2002).

\section{Results and Discussion}

Five key categories emerged from the data:

1. The impact of the International Towers physical environment on performance, engagement and gratitude.

2. The role of 'Carpe Diem' values-based leadership in extending the utility of activity-based working.

3. Expressions of purpose, pride and well-being.

4. Issues in making a transition to a new way of working.

5. How spatial change (i.e., moving to the International Towers site) can be a powerful facilitator of corporate cultural change.

\subsection{Impact of physical environment: Performance, engagement and gratitude}

Many participants from all four categories of interviewees commented on the impact of working in a well-designed, 'green' physical environment and how that supported job performance.

Those working in A-FO environments commented on how much they appreciated being able to determine themselves where, when and how they carried out their work activities, and how this increased sense of autonomy felt empowering. Many reported noticeable improvements in performance both in terms of quantity and in terms of the quality of their work. The ability to hold meetings in an open setting was much appreciated by many and this, more open style of working, had a number of significant benefits including improved information flows.

One of the great things about the space is the big meeting tables, they're not in offices - they're out on the floor. We've probably seen about $50 \%$ of our meetings shift to an open space now ... the benefit is that there's an improved flow of information between people.

Others commented on how their level of engagement and work satisfaction had increased. One tenant-partner talked about how coming into an agile environment not only improved communication flow amongst various teams, but had also lead to greater empowerment for individual staff and greater flexibility and employee engagement. Such benefits have been found in other A-FO workspaces.

However, there were a few perceived difficulties with the A-FO environments including individually differing needs for privacy and interaction, and a need for some level of personalisation and space ownership. These are common issues with A-FO environments and can be overcome by consistent monitoring and subsequent updating 
of the office environment in order to meet employee's emerging needs (AppelMeulenbroek et al. 2011). Indeed, this speaks to the importance of individualistic approach to design that takes into account idiosyncratic work styles and activity patterns, rather than simply rolling out an A-FO design based on general concepts.

Others commented on the overall design of the building and the associated external precincts and how the openness, space and increased natural light made them feel more positive and engaged in their work:

I definitely attribute some of the excitement around doing things differently to the fact that we have this very innovative kind of new office space ... all in all very engaged and very thankful to be in the space.

This sense of gratitude was also expressed by a number of service staff. One who started as a cleaner working for a property contractor has progressed from Site Manager, to Area Manager. Now Executive Manager, in charge of Housekeeping for International Towers, managing 200 people she says:

I always try to put my case as an example, like, if you want, you can. Look at me. My English was nothing, and I was a toilet cleaner, the bottom of the bottom of the cleaning jobs. ... this place motivates me to be the best I can be ...

Indeed, both service staff and tenant-partners expressed gratitude towards the International Towers building managers who were strongly seen as role modelling positive leadership behaviours such as inclusiveness, consideration, passion and having the courage of their convictions. The concept of 'gratitude' may seem somewhat out of place in an evaluation of an office building, yet work-specific gratitude can be an important buffer against burnout, depression, and depersonalisation and is positively related to work engagement and performance (Lanham et al. 2012).

\subsection{Beyond activity-based working: The role of values-based leadership}

The strong emphasis on sustainability, values, culture, community and respect for indigenous heritage are key factors that distinguish a 'Carpe Diem' approach from typical AFO workplaces. This emphasis on values was widely recognised by many participants, due in large part to the explicit and consistent role modelling of these principles by the International Towers building management leadership team and the service staff.

As previously argued, a flourishing workplace requires the adroit pairing of the right type of built environment and physical layout with the right kind of psychological or sociological context. In this case the 'Carpe Diem' building leadership team were seen as being highly committed to these values, and they clearly delineated a specific set of values which are consistently and demonstrably enacted - thus setting the right context for a flourishing workplace. For example, the principles of sustainability and responsibility central to the 'Carpe Diem' philosophy were notably enacted by the International Towers building leadership team's insistence on an ethical and transparent supply chain providence, even down to the granular level of umbrellas and staff uniform procurement. The 
International Towers building management refused to purchase items such as lobby umbrellas and staff uniforms from companies that could not provide proof of ethical manufacture and supply chain. These took some time to procure, but this became an important living symbol and day-to-day embodiment of the building management's commitment to the 'Carpe Diem' philosophy. The impact of this attention to detail resonated strongly with all those interviewed. One tenant-partner commented:

I've heard the umbrella story ... I guess when you hear about these stories, it is quite inspiring and it makes us want to be a better organisation, and hopefully our staff to be better people too.

These kinds of stories, which encapsulate specific value-based narratives, can become important attractor points for the whole community (Goodwyn 2013); points that inspire a more conscious approach to creating a positive working environment.

The stories associated with these procurement and management processes have now become part of the narrative associated with the 'Carpe Diem' space. Such narratives can have a powerful impact on organisational culture (Bartel and Garud 2009), and in this case, have formed an important backdrop in the creation of a flourishing workplace environment.

\subsection{A sense of purpose, pride and well-being}

Given the above findings it is not surprising that a number of respondents expressed a great deal of pride and purpose in their association with the 'Carpe Diem' community:

... the Carpe Diem communities, I see that as a neighbourhood. I feel like people coming together, we have shared values, and have intention to make this place better than they found it, and leave it for the next generation in a better shape than we actually found it ... absolutely I think everyone who's involved in the project, we believe in it, and we want to make a difference.

Others warmed to the positive energy and purpose central to the Carpe Diem philosophy

...the Carpe Diem meaning, that was (my) inspiration. Seize the moment. Make the most of what you have right now, to be a better person, better organisation, better enterprise, better community. Come to work every day and leave better off. Seize it. Seize what we've got to provide you with and take it and go for it. Optimise it. Work it hard.

Others made explicit links between the building design, leadership and individual wellbeing: 
...in my experience people thought that it was the responsibility of the individual person within a building to maintain their own wellness, but I think you need to curate spaces that encourage better behaviours ...

The above observed links between pride, purpose and engagement and well-being are well-established in the literature (Harter et al. 2003). Employees who take pride in their role and have a strong sense of purpose in their work tend to be more resilient, and this is further enhanced when leadership displays authentic and positive characteristics (Harland et al. 2005). Further, Brunetto et al. (2012) found that job satisfaction, wellbeing and engagement were strongly linked to organisational commitment and turnover intentions in policing contexts. Echoing Brunetto et al.'s (2012) findings it is noteworthy that the turnover of security staff at International Towers is approximately $10 \%$ compared to an industry average of between $50 \%$ and $400 \%$ per year (Bitzer 2006).

\subsection{Transition issues}

It is interesting to note that overall there were minimal 'negative' comments about the 'Carpe Diem' ethos. Of the 350 pages of transcribes, there were less than five pages of 'negative' comments (approximately 1.4\%). It may be that those interviewed felt they were somehow not able to be completely candid, but given that anonymity was guaranteed (unless individuals gave specific permission to allow themselves to be identified) we felt this was unlikely, and we are more inclined to conclude that there was a genuine overall positive response.

It is noteworthy that virtually all the 'negative' comments were about concerns about the transition to a new working environment. Some of respondents talked about the challenges of making a move to a new physical location that promoted a new philosophical approach to working. One tenant-partner talked about the initial hesitancy of some staff in making the transition.

“... a lot of our employees in retrospect were quite hesitant about the move, because they didn't know what it as going to be like. And a lot of our clients are actually situated in the CBD. So, it would have made the whole journey a lot more difficult or challenging I guess. But, we recently celebrated our first birthday in this office".

Such concerns and 'negative' comments seemed to reflect typical human reactions that arise when faced with uncertainty and unpredictable change contexts (Bordia et al. 2004). However, many of these transition issues can be overcome by an induction process designed to facilitate a positive transition into the International Towers precinct. Indeed reports indicated that the orientation tours and briefing sessions around the broader connections and values with tenant-partners did in fact help staff feel that they were part of the 'Carpe Diem' community.

...One of the things that guided tour service offers when they first arrive or they're first getting involved, it's setting up those initial expectations, those initial 
conditions. Setting up the standard of what the service provision and the involvement in the community is in a way that says, "Right, this is different. This is new. This is what we do." And then they can expect that there on in, which is representative of the philosophy really.

\subsection{Spatial change as a facilitator of corporate cultural change}

We found that a number of respondents talked about how physically moving to a new, different type of office environment had a significant impact on their organisation culture.

...I think that the space encourages that type of thinking as well. Because I imagine like if we were in our old space, which was a very traditional office with brown carpet, cream walls, cushiony seats and all of that jazz, would people feel like they're inspired to do something different? Possibly not, so yeah I definitely attribute some of the excitement around doing things differently to the fact that we have this very innovative kind of new office space"

Others thought that it was the ethos associated with the 'Carpe Diem' community in conjunction with the International Towers physical design that made the real difference:

I think that (positive change) is partly due to the actual physical place but probably more so due to the passion that is shown by everyone (in the Carpe Diem community). ... they inspired us, sharing their vision and (that) really, resonated with everyone.

The existing literature in this area reports that spatial change can indeed be used to facilitate corporate cultural change (for additional information see Skogland and Hansen 2017). However, typically past research has focused on performance metrics or individual well-being (MacNaughton et al. 2015; Mulville et al. 2016) rather than more systemic organisational cultural issues. We see this as being a prime area for future, more in depth research on positive organisational culture.

\subsubsection{The PBWE: Relation to Positive Psychology Constructs}

Typically, physical aspects of the workplace are assessed by their relation to factors such as performance, physical and mental well-being or the extent to which the building itself avoids 'sick building syndrome' (Redlich et al. 1997). However, the above results and discussion can be usefully viewed through the lens of a range of positive psychology theories, and this approach give us the potential to ground such studies on established psychological frameworks. One key framework is Selfdetermination Theory (Ryan and Deci 2000).

Self-determination theory (SDT) is a macro theory of human motivation that has developed from initial research on individual motivations and has now expanded to 
include systemic research on organisations and other life domains (Deci et al. 2017). SDT posits that all individuals have three basic psychological needs-for competence, autonomy, and relatedness. The satisfaction of these three needs promotes autonomous motivation, high-quality performance and personal wellbeing.

Autonomous motivation is evidenced when people are engaged in activities whilst holding a strong sense of willingness and volition. Autonomous motivation can be manifested even when tasks have been delegated to the person and may even be initially perceived as unpleasant. The key point here is that when individuals understand the purpose and importance of their work, when they feel ownership and autonomy in their roles, and when they receive clear feedback and appropriate support, they are likely to become more autonomously motivated. This is important for a number of reasons, including the findings that autonomous motivation at work is associated with less burnout (Fernet et al. 2010), greater work performance (Kuvaas 2009), lower turnover intentions (Richer et al. 2002), and in some cases company profitability (Preenen et al. 2016).

When the three basic psychological needs of competence, autonomy, and relatedness central to SDT are met, employees have less exhaustion (Van Den Broeck et al. 2008), greater enjoyment of their work (Andreassen et al. 2010), put in more personal effort (De Cooman et al. 2013) and experience higher hedonic and eudaimonic well-being (Gillet et al. 2012).

It is noteworthy that, to date, the SDT research in organisations has focused on the social context, for example, leadership style, the interpersonal atmosphere of a workplace, and conditions such as pay or communication styles (Deci et al. 2017; Grant 2014).

To the best of our knowledge there has been no research that has examined how the physical work environment itself can influence factors such positivity, competence, autonomy and relatedness. Yet, given that the built workplace environment can have a significant impact on employees in terms of performance and well-being (Brunia et al. 2016; Mulville et al. 2016), it seems possible that the built environment itself can either facilitate or hinder the satisfaction of the three basic psychological needs central to SDT. In short, the interaction effects between a positive built environment and positive leadership have not as yet been studied from the perspective of SDT, and there is much that can be learnt from a positive psychology perspective about how to create truly flourishing workplaces.

The 'Carpe Diem' ethos would, on the prima facia reports of those interviewed, appear to rate highly on the key facets of SDT; competence, autonomy and relatedness. The competence aspect is evidenced in the reports that emphasise how the 'Carpe Diem' ethos has helped employees develop on both a professional and personal level; the autonomy aspects are evidenced in the reports that talk about having more choice in the workplace; and the relatedness aspect is evidenced in the many reports that describe the feeling of connectedness and purpose that pervade the 'Carpe Diem' community. The question now arises as how to begin to quantify such aspects in relation to the PBWE.

\subsubsection{Measurement and Evaluation Models}

There are a number of existing models that are used to evaluate the physical workplace environment. For example, the Leadership in Energy and Environmental Design 
(LEED) is a rating system devised by the United States Green Building Council (USGBC) to evaluate the environmental performance of a building and encourage market transformation towards sustainable design. LEED is a multi-faceted approach with a wide range of check points including multiple ratings for each category of; location and transportation; sustainability; water efficacy; energy and atmosphere; materials, resources and recycling; indoor environmental quality; innovation and regional priority. Projects are rated with allocation of a number of points from a basic 'certified' level of 40 points through to the top 'platinum' level of 110 points. In Australia the Green Building Council of Australia (GBCA) provides a similar assessment process, but awards a 'star' rating with six stars being the highest category. Such measurement and evaluation models are well-used and have been developed and finetuned over many years.

From a psychological perspective there have been numerous measurement and evaluation approaches to measuring individual psychological or cultural aspects of the workplace. These include Psychological Capital (Luthans et al. 2007) which encompasses aspects such as hope, efficacy, resilience, and optimism in the workplace; organisational citizenship (Bateman and Organ 1983); or creative climate (Isaksen et al. 1999). However, although many of these approaches consider individual and collective emotions and values; none look from a theoretically-grounded positive psychology perspective, at how working in a specific building makes people feel. If we are to establish a positive psychology of the PBWE we need to develop frameworks and measures that allow us to quantify salient psychological factors of the PBWE.

\subsubsection{SDT and the Positive Built Workplace Environment Scale}

As previously argued SDT provides an established meta-theory of human motivation of theoretical relevance to the PBWE. Indeed, the empirical findings of this initial case study support the use of SDT as a foundational framework for measuring the extent to which the subjective experience of working in a specific building or space can contribute to the need satisfaction of autonomy, competence and relatedness for individuals, teams and organisations and thus help create a flourishing workplace.

There are well established SDT measures for a wide range of life domains including people's intrinsic and extrinsic life goals or aspirations; religious self-regulation; healthrelevant behaviours; mindfulness; and motives for participating in physical activities (see http://selfdeterminationtheory.org/questionnaires for full listing). Two existing SDT questionnaires that focus on the workplace are the Work Climate Questionnaire (WCQ; Baard et al. 2004) and the Basic Psychological Need Satisfaction at Work Scale (BPNSWS; Deci and Ryan 2000). However, neither of these specifically makes reference to the physical workplace or the built environment. The WCQ utilises items such as "I feel that my manager provides me choices and options", and the BPNSWS utilises items such as "At work, I feel a sense of choice and freedom in the things I undertake".

We propose an adaption of the BPNSWS - the Positive Built Workplace Environment Scale (PBWES). This new 15-item scale is yet to be psychometrically validated, but may provide a useful starting point for assessing the PBWE from a SDT perspective. As can be seen from Table 1, the items on the PBWES are designed to assess the extent to which being in the building and or its associated precincts simulate feelings of autonomy, competence and relatedness in those who work there. 
The PBWES (see Table 1) aims to measure the impact of the building and its precincts on individuals from a positive psychology perspective. Such a scale has the potential to contribute to our understanding of the relationship between the build workplace environment and psychological factors that contribute to human flourishing. However, we also need a framework that allows assessment of the physical aspects of the actual building and its precincts from a positive psychology perspective. Maslow's Hierarchy of Needs may provide a useful framework.

\subsubsection{Maslow's Hierarchy of Needs for the Positive Built Workplace Environment}

Maslow's (1954) Hierarchy of Needs is a motivational theory comprising a five tier model of human needs, typically depicted as hierarchical levels within a pyramid. The two lower-order levels are considered physiological and safety needs, while the top three levels of the pyramid represent growth needs. The five levels from highest to lowest are 1) Self-actualisation - the realisation of a person's full potential; 2) Esteem the need for self-esteem and respect; 3) Belonging - the need to feel connected to social groups; 4) Safety - the need for personal and financial safety; and 5) Physiological needs - the physical requirements for human survival, including adequate air, water, food and the like. If these are not met, humans cannot function properly and will ultimately die or fail. This can be usefully adapted to delineate a hierarchy of needs for the PBWE.

Table 1 The Positive Built Workplace Environment Scale (PBWES)

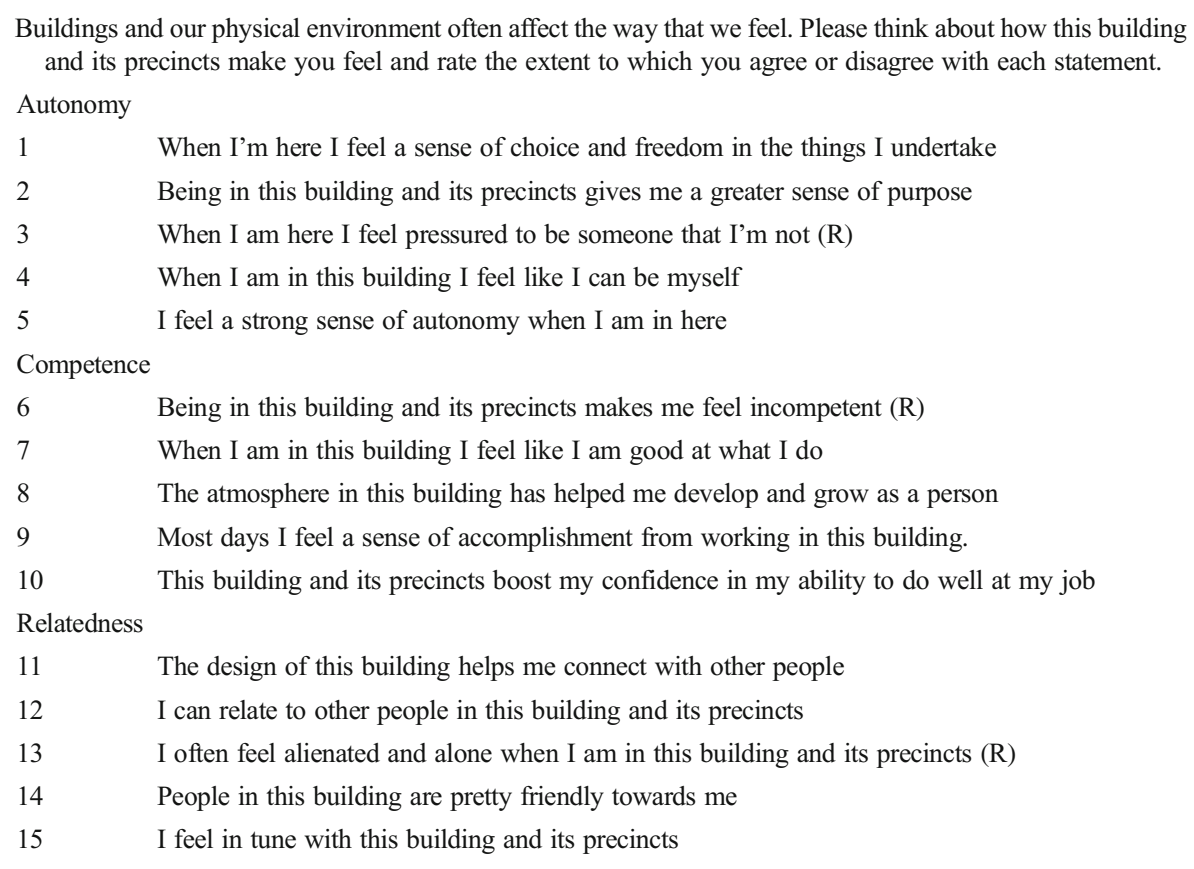

$(\mathrm{R})=$ Reverse scored 
In terms of the hierarchy of needs for the PBWE: at the bottom level (See Fig. 1, level 5) we have the physiological needs that are supported by the built workplace environment. These can range from the minimum amount of (for example) space, light, air quality, health and safety requirements needed to allow the work to be done, to the highest quality physical space as represented by GBCA's 'six star' rating or LEED's 'platinum' level of 110 points.

At the next level (level 4) we have safety needs. These consist of elements as a physically safe, injury-free and bullying-free environment, fair pay and remuneration, reasonable benefits, properly defined role descriptions, and an appropriate management structure. Safety in this context also incorporates the feeling of predictability and consistency (Walumbwa and Schaubroeck 2009); people in the building need to feel that the services provided by the building management and the building itself are reliable and robust. As in level five, these facets can range from a bare minimum to examples of world best practice.

At the next level (level 3) we have belongingness needs. The actual physical space should be designed to facilitate positive interactions and connections between individuals and groups. Such design should occur at the micro level as represented in welldesigned A-FO workplaces, and at the macro level as represented by the design of the actual building and its precincts. Such connectedness and belongingness can also be facilitated by the provision of high quality ICT services in the building (Leader-Chivee et al. 2008). Again, the extent to which the physical space purposefully facilitates belongingness can range from the minimum of being a designer's after-thought, to being a central principal around which the whole building is designed. As previously discussed, when an employee feels as though they 'belong' at work, they are far more likely to develop a sense of purpose in their work (Gagné and Deci 2005).

At level 2 we have the esteem needs - the need for self-esteem and respect. These are the needs that when met, can unleash an employee's passion, creativity and sense of purpose in their work (Kinjerski and Skrypnek 2006). In terms of the built

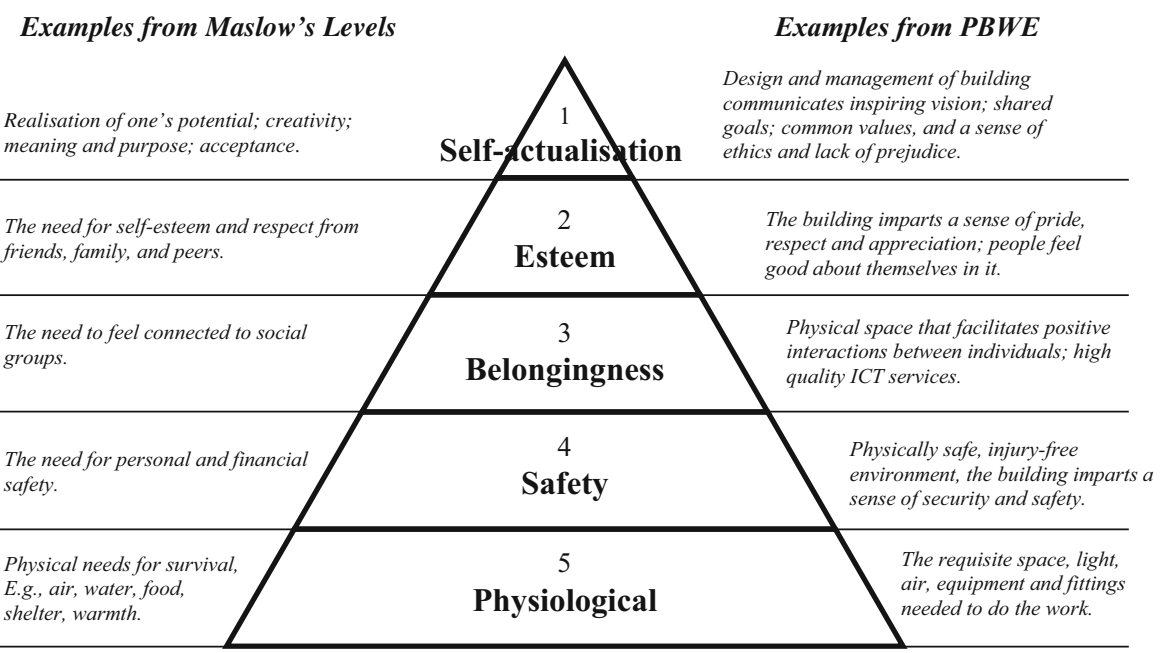

Maslow's Hierarchical Levels of Needs

Fig. 1 Maslow's Hierarchy adapted for the built environment 
environment, the building and its precincts should impart a sense of respect and appreciation to those who are in the building. This could be evidenced (for example) in the pride shown by employees in their relationship to the building (Oliveira 2005).

At level 1 we have the self-actualisation needs - the need for personal fulfilment and the need to grow and develop. In the workplace, self-actualisation equates to realising one's true potential. This requires a clear vision of one's purpose and values (Blanchard and Stoner 2004). The design and management of the building and its precents needs to communicate an inspiring vision: one that provides the community with a shared goal of self-fulfilment, common values, and a sense of ethics and lack of prejudice. There needs to be a depth of detail in this vision, but also a degree of flexibility that, whilst reinforcing the values and purpose of the community, still allows for the ongoing evolution and development of its individual members (Baches 2016).

\subsubsection{The Need for Values Alignment between Tenant Organisation and Building Management}

Thus far we have discussed the notion of a positive psychology of PBWE from the perspective of the building and precinct design, the espoused values and culture of a 'Carpe Diem' philosophy and its impact on employees and those that work in the buildings. It should be noted that one could have an extremely well-designed building, positive and collaborative building management and service staff, and an enthusiastic group of potential employees - but - without appropriate leadership in the tenant organisations we run the very real risk of failing to create a truly flourishing workplace. In short, there needs to be a strong alignment between the values of the building management and those of the tenant organisation. In the current case study this kind of alignment was achieved by the building management taking time to ensure that potential tenants thoroughly understood and subscribed to the cultural and philosophical values central to the 'Carpe Diem' approach, as well as encouraging employees of tenant-partners to undertake the 'Carpe Diem' induction process.

Figure 2 illustrates the proposed relationship between 1) the physical built environment, 2) psychological aspects central to SDT, and 3) the nature or culture of the tenantpartner organisation. When these three key facets of the PBWE are appropriately aligned they produce a need satisfying experience for those that work in or in association with the building. This in turn produces a 'positive ethos' which would be evidenced by higher workplace performance, greater innovation and creativity and enhanced personal and organisational well-being. This proposed model is yet to be empirically tested, and this could form a valuable avenue for future research into the positive psychology of the built workplace environment.

\section{Summary}

To date research has focused on building design, internal office space fit-out and on the leadership of organisations: the role of building management has been largely overlooked as a factor that can contribute to a positive workplace environment. The present research suggests that this kind of holistic approach to the design, leasing and management of contemporary workplaces, in this case represented by the 'Carpe Diem' philosophy, has 


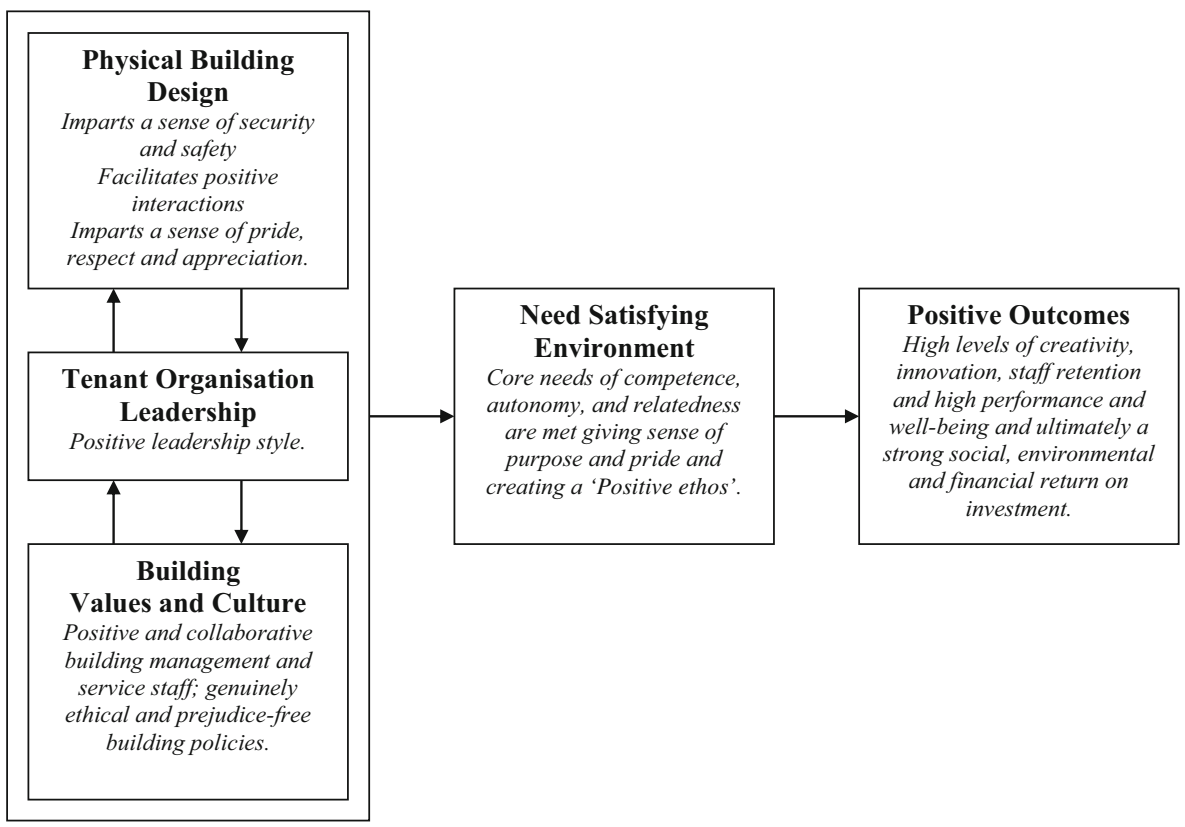

Fig. 2 Theoretical model of relationships leading to positive outcomes

the potential to enrich the lived experience of organisations and their employees and ultimately the broader community. As the nature of work evolves and changes at an everincreasing pace, we hope that our paper helps further develop our understanding of how to better develop positive workplace environments that will support future organisational and individual development in a sustainable, humanistic fashion.

Funding This study was funded by LendLease IRMA Project ID: 195702.

\section{Compliance with Ethical Standards}

Conflict of Interest Disclosure Statement In accordance with Springer policy and our ethical obligation as researchers, we are reporting that this research was funded by LendLease and that the University of Sydney received said funding. The researchers themselves do not hold any financial interest in LendLease or International Towers or any company or business that may be affected by the research reported in the enclosed paper.

\section{References}

Allen, J. G., MacNaughton, P., Satish, U., Santanam, S., Vallarino, J., \& Spengler, J. D. (2016). Associations of cognitive function scores with carbon dioxide, ventilation, and volatile organic compound exposures in office workers: A controlled exposure study of green and conventional office environments. Environmental Health Perspectives, 124(6), 805-812.

Andreassen, C., Hetland, J., \& Pallesen, S. (2010). The relationship between "Workaholism", basic needs satisfaction at work and personality. European Journal of Personality, 24(1), 3-17.

Appel-Meulenbroek, R., Groenen, P., \& Janssen, I. (2011). An end-User's perspective on activity-based office concepts. Journal of Corporate Real Estate, 13(2), 122-135.

Ashkanasy, N. M., Ayoko, O. B., \& Jehn, K. A. (2014). Understanding the physical environment of work and employee behavior: An affective events perspective. Journal of Organisational Behavior, 35(8), 1169-1184. 
Baard, P. P., Deci, E. L., \& Ryan, R. M. (2004). Intrinsic need satisfaction: A motivational basis of performance and well-being in two work settings. Journal of Applied Social Psychology, 34(1), 2045-2068.

Baches, M. B. E. (2016). Hierarchy of Needs: Application in Urban Design and Community-Building. Retrieved from http://mallorybaches.com/discuss/2016/1/26/hierarchy-of-needs.

Bakker, A. B. (2011). An evidence-based model of work engagement. Current Directions in Psychological Science, 20(4), 265-269.

Bartel, C. A., \& Garud, R. (2009). The role of narratives in sustaining Organisational innovation. Organization Science, 20(1), 107-117.

Bateman, T. S., \& Organ, D. W. (1983). Job satisfaction and the good soldier: The relationship between affect and employee "citizenship.". The Academy of Management Journal, 26(4), 587-595.

Bishop, P. (2004). Despised, slippery and untrustworthy? An analysis of reputation in estate agency. Housing Studies, 19(1), 21-36.

Bitzer, E. (2006). Stratagies for cutting turnover. Security Management, May. Retrieved from https://sm. asisonline.org/Pages/Strategies-for-Cutting-Turnover.aspx.

Blair, E. (2015). A reflexive exploration of two qualitative data coding techniques. Journal of Methods and Measurement in the Social Sciences, 6(1), 14-29.

Blanchard, K., \& Stoner, J. (2004). The vision thing: Without it You'll never be a world-class organization. Leader to Leader, 2004(31), 21-28.

Bordia, P., Hunt, E., Paulsen, N., Tourish, D., \& DiFonzo, N. (2004). Uncertainty during Organisational change: Is it all about control? European Journal of Work and Organisational Psychology, 13(3), 345-365.

Bouncken, R. B., Aslam, M. M., \& Reuschl, A. J. (2018). The dark side of entrepreneurship in Coworkingspaces. In A. Tur Porcar \& D. Ribeiro Soriano (Eds.), Inside the mind of the entrepreneur (pp. 135-147). London: Springer.

Brunetto, Y., Teo, S. T., Shacklock, K., \& Farr-Wharton, R. (2012). Emotional intelligence, job satisfaction, well-being and engagement: Explaining Organisational commitment and turnover intentions in policing. Human Resource Management Journal, 22(4), 428-441.

Brunia, S., Been, I. D., \& Voordt, T. (2016). Accommodating new ways of working: Lessons from best practices and worst cases. Journal of Corporate Real Estate, 18(1), 30-47.

Cameron, K. (2012). Positive Leadership: Strategies for Extraordinary Performance. San Francisco: BerrettKoehler Publishers.

Cameron, K., \& Dutton, J. (2003). Positive Organisational scholarship: Foundations of a new discipline. San Francisco: Berrett-Koehler Publishers.

Cameron, K. S., Dutton, J. E., \& Quinn, R. E. (Eds.). (2003). Positive Organisational scholarship: Foundations of a new discipline. San Francisco: Berrett-Koehler.

Cameron, K. S., Bright, D., \& Caza, A. (2004). Exploring the Relationships between Organizational Virtuousness and Performance. American Behavioral Scientist, 47(6), 766-790.

Chandrasekar, K. (2011). Workplace environment and its impact on Organisational performance in public sector Organisations. International Journal of Enterprise Computing and Business Systems, 1(1), 1-19.

Datta, B. (2015). Assessing the effectiveness of authentic leadership. International Journal of Leadership Studies, 9(1), 62-75.

De Cooman, R., Stynen, D., Van Den Broeck, A., \& Sels, L. (2013). How job characteristics relate to need satisfaction and autonomous motivation: Implications for work effort. Journal of Applied Social Psychology, 43(6), 1342-1352.

Deci, E. L., \& Ryan, R. M. (2000). The "what" and "why" of goal pursuits: Human needs and the selfdetermination of behavior. Psychological Inquiry, 11(4), 227-268.

Deci, E. L., Olafsen, A. H., \& Ryan, R. M. (2017). Self-determination theory in work organizations: The state of a science. The Annual Review of Organizational Psychology and Organizational Behavior, 4, 19-43.

Dweck, C. S. (2016). The remarkable reach of growth mind-sets. Scientific American Mind, 27, 36-41.

Fernet, C., Gagne, M., \& Austin, S. (2010). When does quality of relationships with coworkers predict burnout over time? The moderating role of work motivation. Journal of Organisational Behavior, 31(8), $1163-1180$.

Fuzi, A. (2015). Co-working spaces for promoting entrepreneurship in sparse regions: The case of South Wales. Regional Studies, Regional Science, 2(1), 462-469.

Gagné, M., \& Deci, E. L. (2005). Self-determination theory and work motivation. Journal of Organisational Behavior, 26(4), 331-362.

Gensler, M. (2005). These four walls: The real British office. London: Gensler.

Gillet, N., Fouquereau, E., Forest, J., Brunault, P., \& Colombat, P. (2012). The impact of Organisational factors on psychological needs and their relations with well-being. Journal of Business and Psychology, 27(4), 437-450. 
Goodwyn, E. (2013). Recurrent motifs as resonant attractor states in the narrative field: A testable model of archetype. The Journal of Analytical Psychology, 58(3), 387-408.

Grant, A. M. (2006). Workplace and executive coaching: A bibliography from the scholarly business literature. In D. R. Stober \& A. M. Grant (Eds.), Evidence based coaching handbook (pp. 367-387). New York: Wiley.

Grant, A. M. (2012). ROI is a poor measure of coaching success: Towards a more holistic approach using a well-being and engagement framework. Coaching: An International Journal of Theory, Research and Practice, 5(2), 1-12.

Grant, A. M. (2013). Steps to solutions: A process for putting solution-focused coaching principles into practice. The Coaching Psychologist, 9(1), 36-44.

Grant, A. M. (2014). Autonomy support, relationship satisfaction and goal focus in the coach-Coachee relationship: Which best predicts coaching success? Coaching: An International Journal of Theory, Research and Practice, 7(1), 18-38.

Guthrie, J. P. (2001). High-involvement work practices, turnover, and productivity: Evidence from newZealand. The Academy of Management Journal, 44(1), 180-190.

Harland, L., Harrison, W., Jones, J. R., \& Reiter-Palmon, R. (2005). Leadership behaviors and subordinate resilience. Journal of Leadership \& Organisational Studies, 11(2), 2-14.

Harter, J. K., Schmidt, F. L., \& Keyes, C. L. (2003). Well-being in the workplace and its relationship to business outcomes: A review of the Gallup studies. In C. L. M. Keyes \& J. Haidt (Eds.), Flourishing: Positive Psychology and the Life Well Lived (Vol. 2, pp. 205-224). Washington D.C: American Psychological Association.

Herzberg, F. (1964). The Motivation-Hygiene Concept and Problems of Manpower. Personnel Administrator, 27(1), 3-7.

Isaksen, S. G., Lauer, K. J., \& Ekvall, G. (1999). Situational Outlook Questionnaire: A Measure of the Climate for Creativity and Change. Psychological Reports, 85(2), 665-674.

Johns, T., \& Gratton, L. (2013). The Third Wave of Virtual Work. Harvard Business Review, 91(1), 66-73.

Kinjerski, V., \& Skrypnek, B. J. (2006). Creating Organisational Conditions That Foster Employee Spirit at Work. Leadership and Organization Development Journal, 27(4), 280-295.

Kuvaas, B. (2009). A Test of Hypotheses Derived from Self-Determination Theory among Public Sector Employees. Employment Relations, 31(1), 39-56.

Lanham, M., Rye, M., Rimsky, L., \& Weill, S. (2012). How Gratitude Relates to Burnout and Job Satisfaction in Mental Health Professionals. Journal of Mental Health Counseling, 34(4), 341-354.

Leader-Chivee, L., Hamilton, B. A., \& Cowan, E. (2008). Networking the Way to Success: Online Social Networks for Workplace and Competitive Advantage. People and Strategy, 31(4), 40-46.

Leblebici, D. (2012). Impact of Workplace Quality on Employee's Productivity. Journal of Business, Economics and Finance, 1(1), 38-49.

Lomas, T., \& Ivtzan, I. (2016). Second Wave Positive Psychology: Exploring the Positive-Negative Dialectics of Wellbeing. Journal of Happiness Studies, 17(4), 1753-1768.

Luthans, F., Avolio, B. J., Avey, J. B., \& Norman, S. M. (2007). Psychological Capital: Measurement and Relationship with Performance and Job Satisfaction. Personnel Psychology, 60(1), 541-572.

MacNaughton, P., Pegues, J., Satish, U., Santanam, S., Spengler, J., \& Allen, J. (2015). Economic, Environmental and Health Implications of Enhanced Ventilation in Office Buildings. International Journal of Environmental Research and Public Health, 12(11), 14,709.

Maslow, A. H. (1954). Motivation and Personality. Oxford: Harpers.

Maslow, A. H. (1968). Towards a Psychology of Being. New York: Wiley \& Sons.

Miller, A. (2008). A Critique of Positive Psychology—or 'the New Science of Happiness'. Journal of Philosophy of Education, 42(3-4), 591-608.

Morse, J. M., Barrett, M., Mayan, M., Olson, K., \& Spiers, J. (2002). Verification strategies for establishing reliability and validity in qualitative research. International Journal of Qualitative Methods, 1, 13-22.

Mulville, M., Callaghan, N., \& Isaac, D. (2016). The Impact of the Ambient Environment and Building Configuration on Occupant Productivity in Open-Plan Commercial Offices. Journal of Corporate Real Estate, 18(3), 180-193.

Neuendorf, K. A. (2002). The Content Analysis Guidebook. Thousand Oaks: Sage Publications.

Oliveira, M. (2005). Building Leadership: How Pride in Your Work Leads to Better Attendance and Quality. Performance Improvement, 44(7), 5-6.

Pierce, J. L., Gardner, D. G., \& Crowley, C. (2016). Organization-Based Self-Esteem and Well-Being: Empirical Examination of a Spillover Effect. European Journal of Work and Organisational Psychology, 25(2), 181-199. 
Preenen, P., Oeij, P., Dhondt, S., Kraan, K., \& Jansen, E. (2016). Why Job Autonomy Matters for Young Companies' Performance: Company Maturity as a Moderator between Job Autonomy and Company Performance. World Review of Entrepreneurship, Management and Sustainable Development, 12(1), 74-100.

Prochaska, J. M. (2000). A Transtheoretical Model for Assessing Organisational Change: A Study of Family Service Agencies' Movement to Time-Limited Therapy. Families in Society, 81(1), 76-84.

Redlich, C. A., Sparer, J., \& Cullen, M. R. (1997). Sick-Building Syndrome. The Lancet, 349(9057), 1013-1016.

Richer, S., Blanchard, C., \& Vallerand, R. (2002). A Motivational Model of Work Turnover. Journal of Applied Social Psychology, 32(10), 2089-2113.

Ruostela, J., Lönnqvist, A., Palvalin, M., Vuolle, M., Patjas, M., \& Raij, A.-L. (2015). 'New Ways of Working'as a Tool for Improving the Performance of a Knowledge-Intensive Company. Knowledge Management Research and Practice, 13(4), 382-390.

Ryan, R. M., \& Deci, E. L. (2000). Self-Determination Theory and the Facilitation of Intrinsic Motivation, Social Development, and Well-Being. American Psychologist, 55(1), 68-78.

Sanderson, D. C., \& Edwards, V. M. (2016). Determinants of Satisfaction Amongst Tenants of Uk Offices. Journal of Corporate Real Estate, 18(2), 102-131.

Seligman, M. E., \& Csikszentmihalyi, M. (2000). Positive Psychology: An Introduction. American Psychologist, 55(1), 5-14.

Skogland, M. A. C., \& Hansen, G. K. (2017). Change Your Space, Change Your Culture: Exploring Spatial Change Management Strategies. Journal of Corporate Real Estate, 19(2), 95-110.

Spence, G. B., \& Grant, A. M. (2013). Coaching and Well-Being: A Brief Review of Existing Evidence, Relevant Theory and Implications for Practitioners. In I. Boniwell \& S. David (Eds.), Oxford Handbook of Happiness (pp. 1009-1025). Oxford: Oxford Univeristy Press.

Srivastva, S., \& Cooperrider, D. L. (1999). Appreciative Management and Leadership: The Power of Positive Thought and Action in Organizations. New York: Williams.

Streufert, S., Pogash, R., \& Piasecki, M. (1988). Simulation-based assessment of managerial competence: Reliability and validity. Personnel Psychology, 41(3), 537-557.

Thomas, D. R. (2006). A General Inductive Approach for Analyzing Qualitative Evaluation Data. American Journal of Evaluation, 27(2), 237-246

Van Den Broeck, A., Vansteenkiste, M., DeWitte, H., \& Lens, W. (2008). Explaining the Relationships between Job Characteristics, Burnout, and Engagement: The Role of Basic Psychological Need Satisfaction. Work and Stress, 22(3), 277-294.

van Elst, D., \& Meurs, D. (2015). Positive Management: The Relationship between the Psychological Contract, Employee Engagement and Organisational Commitment. Journal of Positive Management, 6(4), 39-52.

Walumbwa, F. O., \& Schaubroeck, J. (2009). Leader Personality Traits and Employee Voice Behavior: Mediating Roles of Ethical Leadership and Work Group Psychological Safety. Journal of Applied Psychology, 94(5), 1275-1286.

Walumbwa, F. O., Avolio, B. J., Gardner, W. L., Wernsing, T. S., \& Peterson, S. J. (2008). Authentic leadership: Development and validation of a theory based measure. Journal of Management, 34(1), 89-126.

White, M. A., \& Waters, L. E. (2015). A Case Study of 'the Good School:' Examples of the Use of Peterson's Strengths-Based Approach with Students. The Journal of Positive Psychology, 10(1), 69-76.

Yudelson, J. (2009). What Is a Green Building? Sustainable Retail Development (pp. 41-65). London: Springer.

Publisher's Note Springer Nature remains neutral with regard to jurisdictional claims in published maps and institutional affiliations.

\section{Affiliations}

\section{Anthony M. Grant ${ }^{1} \cdot$ Sean A. O'Connor ${ }^{1} \cdot$ Ingrid Studholme $^{1}$}

1 Coaching Psychology Unit, School of Psychology, University of Sydney, Sydney, New South Wales 2006, Australia 